\title{
DOSSIER
}

\section{“CON SU PIEL NATURAL". LA EXHIBICIÓN MUSEOLÓGICA DE CUERPOS Y RESTOS HUMANOS PRESERVADOS}

\author{
Luis Ángel Sánchez Gómez \\ Departamento de Prehistoria, Historia Antigua y Arqueología \\ Facultad de Geografía e Historia \\ Universidad Complutense. Madrid \\ Email: langel@ucm.es \\ ORCID iD: http://orcid.org/0000-0002-1073-7714
}

Recibido: 14 diciembre 2018; Aceptado: 26 marzo 2019

Cómo citar este artículo/Citation: Sánchez Gómez, Luis Ángel (2019), “'Con su piel natural'. La exhibición museológica de cuerpos y restos humanos preservados", Asclepio, 71(2): p274. https://doi.org/10.3989/asclepio.2019.15

RESUMEN: La exhibición de cuerpos y restos humanos preservados ha sido y continúa siendo habitual en ciertos museos, también en España. Este artículo repasa los contextos expositivos que conducen desde la limitada presencia de restos humanos en las cámaras de curiosidades y los primeros museos de historia natural, hasta su exitosa consolidación en los gabinetes y museos anatómicos (académicos y comerciales) durante el último tercio del siglo XVIII y todo el XIX. Se presta especial atención a la actividad desarrollada por el doctor González Velasco, tanto en sus propios museos como en la Facultad de Medicina de Madrid.

PALABRAS CLAVE: Museos; Restos humanos; Anatomía; Antropología; doctor Velasco.

\section{"WITH THEIR NATURAL SKIN". MUSEOLOGICAL EXHIBITIONS OF PRESERVED HUMAN BODIES AND REMAINS}

ABSTRACT: The exhibition of preserved human bodies and remains was and is still common in some museums, also in Spain. This article reviews the gradual expansion of this exhibitions, from the scarce presence of human remains in the chambers of curiosities and the first natural history museums to the successful consolidation of this kind of exhibits in the anatomical cabinets and museums (both academic and commercial) during the last third of the 18th century and the entire 19th century. Special attention is paid to the activity carried out by Dr. González Velasco, both in its own museums and in the Faculty of Medicine of Madrid.

KEY WORDS: Museums; Human remains; Anatomy; Anthropology; Dr. Velasco. 


\section{INTRODUCCIÓN}

Desde el momento en que los antiguos gabinetes de arte y curiosidades comienzan a transformarse en instituciones cercanas a verdaderos museos, algo que sucede a partir del último tercio del siglo XVIII, quienes acuden a estos sofisticados templos laicos lo hacen seducidos por la posibilidad de contemplar objetos extraordinarios, bellos, la mayoría únicos. Aunque algunos de estos museos muestran llamativos especímenes de historia natural o exóticas piezas procedentes de lejanas culturas, desde sus inicios los más admirados son los que exhiben obras de arte, esencialmente pinturas y esculturas. Por supuesto, en estos centros se pueden contemplar cuerpos humanos muertos, pero son únicamente representaciones, cuerpos pintados sobre lienzos o tablas, o esculpidos en piedra, madera o metal ${ }^{1}$. Pero si hay algo que escapa al sentido original y al propósito esencial de la inmensa mayoría de los museos, sea cual fuere su orientación, es la exhibición de huesos y, menos aún, de cuerpos humanos preservados, o de algunas de sus partes, o de sus órganos ${ }^{2}$. Por muy hermoso que fuere en vida y por muy sugerente que pueda resultar su representación en el ámbito del arte, suele considerarse que un cuerpo humano muerto y preservado ha perdido su belleza, que es materia inerte cuya contemplación no puede resultar placentera ${ }^{3}$. ¿O quizás sí? Bien, aunque es posible que el término "placentero" no defina el estado de ánimo generado de forma mayoritaria ante la visión de restos humanos preservados, sí es cierto que se exhibieron y se exhiben aún en ciertos museos, también en España, con propósitos que pueden ser formativos, moralizantes, estéticos o de mero divertimento.

\section{CÁMARAS DE CURIOSIDADES Y RELICARIOS}

¿Cuándo, cómo, dónde y por qué comienzan a exhibirse cráneos, esqueletos, cuerpos o restos humanos en museos o espacios asimilables? Su presencia es muy reducida en las primeras Kunstkammern y Wunderkammern renacentistas, pues el propósito de estas colecciones es mostrar precisamente lo que su nombre indica: obras de arte y maravillas, ya sean especímenes extraordinarios procedentes del reino natural o singularísimas creaciones del arte y del ingenio humano ${ }^{4}$. Es cierto que en algunas es posible encontrar dientes o fragmentos de huesos, como ocurre en la famosa colección de Juan I de Berry (1340-1416), pero sólo están ahí por su condición de reliquia cristiana. Su esencia maravillosa se debe al poder taumatúrgico que se deriva de su cualidad espiritual, lo que las sitúa fuera de todo proyecto exhibidor de anatomías humanas. Por supuesto, restos humanos elevados a la condición de reliquia cristiana están presentes desde mucho antes y durante mucho tiempo después en las cámaras relicario propias del ámbito religioso. Es evidente que el contexto simbólico y material que articula su acopio y exhibición debe ser singularizado respecto del que ahora nos interesa (las colecciones y museos laicos), pero pienso que resultará interesante hacer alguna observación al respecto.

En primer lugar, es necesario recordar que, a diferencia de lo que ocurre en las cámaras renacentistas, la disposición de las reliquias cristianas no suele facilitar un acceso visual claro y directo a las piezas. Durante la Edad Media y buena parte del Renacimiento las reliquias se guardan en cajas y arcas, y solo algunas se muestran en momentos y circunstancias excepcionales. Su exhibición pública y la intensificación de las llamadas a su veneración tiene una relación directa con el combate contra la Reforma protestante. A partir de entonces, las cámaras relicario más importantes disponen sus reliquias en magníficos relicarios que destacan por la riqueza de sus materiales y la relevancia artística de su factura, no por la espectacularidad ni la visibilidad de los restos humanos que contienen ${ }^{5}$. Parece evidente, por tanto, que la colección y exhibición de restos humanos en contextos cristianos poco tiene que ver con los modelos que se articulan en los gabinetes y museos anatómicos. $Y$ esto es algo que podemos comprobar en Madrid con el que quizás sea el ejemplo más destacado de una cámara relicario del Barroco: la del Real Monasterio de La Encarnación (Sánchez Hernández, 2015). Adentrarse en tan deslumbrante espacio es una experiencia que no debe de diferenciarse mucho de la que sentiríamos al visitar alguna de las mejores cámaras maravillosas del Renacimiento, pero no debido a la impresión generada por las propias reliquias, que apenas se vislumbran, sino por la suntuosidad de los relicarios. Sí, es cierto que la religiosa agustina que se postrara ante tales reliquias en el siglo XVII sentiría e interiorizaría ese espacio y esos objetos de forma muy diferente a la nuestra; pero ni entonces ni ahora se percibe allí la presencia de lo macabro ni, por supuesto, lección alguna de anatomía humana.

Precisamente de forma coetánea al gran momento de esplendor que alcanzan las cámaras relicario del 
Barroco, a partir de las décadas de 1630-1640, también en los gabinetes de curiosidades se dejan notar ciertos cambios. A partir de entonces, algunos incluyen entre sus llamativas piezas una de tipología muy particular, que no es exótica ni maravillosa, pero cuya exhibición resulta habitual desde mucho tiempo atrás gracias al citado fenómeno de las reliquias. Me refiero a la calavera, aunque parece evidente que esta presencia debe ser interpretada como memento mori, ajena de nuevo a cualquier proyecto exhibidor de anatomías humanas ${ }^{6}$. En todo caso, aunque las calaveras hacen entonces esa tímida aparición, no se puede decir que la exhibición de restos humanos resulte habitual en los gabinetes europeos del XVII y comienzos del XVIII. Si nos centramos en el ámbito español ${ }^{7}$, comprobamos que el más destacado coleccionista particular del siglo XVII y uno de los más importantes de Europa, el oscense Vincencio Juan de Lastanosa (1607-1681), no posee ni huesos, ni fetos, ni órganos humanos preservados en su extensa y variada colección (Rey Bueno y López Pérez, 2008). Al igual que otros coleccionistas contemporáneos, sí guarda supuestas petrificaciones humanas y presuntos "huesos de gigantes", pero, como ya se adelantó en nota, la singularidad de las piezas probablemente impide (o al menos dificulta) que sean asimiladas a la condición de restos humanos auténticos, propios de personas reconocibles como tales. Tampoco parece haber contenido restos humanos (pese a los cambios que sufre con el paso del tiempo) el Gabinete Salvador, iniciado por el botánico y farmacéutico catalán Joan Salvador i Boscà (1598-1681), enriquecido de forma muy activa por sus descendientes hasta la década de 1760 y que continúa abierto al público durante casi un siglo después (Pardo Tomás, 2010). En otros países europeos, los gabinetes cuyos propietarios están vinculados de forma más o menos directa con la ciencia, la medicina, la farmacia o la universidad tienden a orientarlos cada vez más hacia la historia natural, y algunos dan cabida a ciertos elementos asociados con lo humano, aunque en realidad se trata de restos considerados por una u otra razón extraños o maravillosos: fetos monstruosos, raras excrecencias óseas o cutáneas (los famosos "cuernos") y las recurrentes momias egipcias. Así ocurre, entre otros, en los gabinetes de Ole Worm (1588-1654), Lodovico Moscardo (1611-1681), Athanasius Kircher (1602-1680), Ferdinando Cospi (1606-1686), Levinus Vincent (1658-1727) o Ralph Thoresby (1658-1725). Es cierto que al menos Kircher muestra un esqueleto humano, ${ }^{8}$ pero se podría afirmar (con todas las cau- telas) que ninguno articula un discurso explícito y reconocible sobre la condición biológica del ser humano.

\section{LOS MUSEOS DE LA ILUSTRACIÓN}

Aunque no se pueden fijar nítidas fronteras temporales, mediado el siglo XVIII el abigarrado gabinete de curiosidades de época barroca se está transformado en algo distinto, aunque no único. Puede acabar asumiendo las características propias del museo de arte, del gabinete arqueológico, del museo de historia natural e incluso del museo anatómico, aunque el desarrollo de este último presenta alguna singularidad. También se comprueba cómo las iniciativas privadas son ahora sustituidas en buena medida por proyectos de instituciones públicas. Aunque gran parte de su esencia queda ya definida en las grandes colecciones reales del XVII, el museo de arte se consolida entonces como el celoso guardián de las obras más bellas y exquisitas creadas por el ser humano, por completo ajeno a la corporeidad carnal de lo humano. Los de carácter arqueológico sí pueden exhibir ciertos restos humanos singulares (momias egipcias y alguna guanche) pero, al igual que ocurría en los gabinetes previos, tampoco aquí se diseñan discursos que vinculen estas piezas con proyectos formativos relacionados con el estudio de la anatomía humana.

Si dirigimos nuestra mirada hacia los nuevos museos de historia natural, comprobamos que la presentación de lo humano, de la condición animal del hombre, es también limitada o, cuanto menos, contradictoria. Es algo que se documenta tanto en las colecciones particulares como en los primeros museos públicos europeos, incluido el Museo Británico, que a comienzos del XIX se deshace de los esqueletos y demás elementos de anatomía humana que habían formado parte de su núcleo fundador original, la colección de Hans Sloane: son enviados al Real Colegio de Cirujanos de Londres, y allí dan origen -junto con la colección anatómica adquirida a John Hunter- a su famoso Hunterian Museum (MacGregor, 1995; Delbourgo, 2017). Algo similar ocurre también en España, donde las colecciones particulares más destacadas de historia natural no parecen haber cobijado elementos de anatomía humana. No los encontramos en la más importante de todas, la organizada en París por Pedro Franco Dávila (1711-1786), adquirida por el Estado español en 1771 con destino al recién crea- 
do Real Gabinete de Historia Natural (Sánchez Almazán y Cánovas Fernández, 2016). Tampoco en las del infante Luis Antonio de Borbón (1727-1785) o el cardenal Francisco de Lorenzana (1722-1804), que tras la muerte del primero acaban reunidas en una única colección (García Martín, 2012; Revenga Domínguez, 2014). Sí es cierto, pese a todo, que durante el último tercio del XVIII los naturalistas continúan interesados por ciertas categorías de lo humano monstruoso. El Real Gabinete de Historia Natural madrileño recibe en 1795 uno de estos "especímenes": los cadáveres de dos siamesas muertas en la villa de Rueda al poco de nacer. Aunque se les practica la autopsia, y pese al debate de índole religiosa y moral que el caso genera, el destino de la singular pieza no parece haber sido muy diferente al de los demás ejemplos de teratología humana que guarda el centro: se preservan en alcohol y quedan fuera de la vista del público (Ruud, 2014). No obstante, se debe destacar que el museo guarda tres esqueletos humanos no patológicos, que quizás sí sean exhibidos (Ruud, 2012: p. 164, nota 540).

El relativo interés que muestran estos museos del XVIII por la exhibición de restos humanos se podría explicar por el hecho evidente de que solo muy avanzado el siglo XIX la historia natural desarrolla un nuevo paradigma morfológico que permite abordar el debate sobre la naturaleza animal del ser humano. Sin embargo, ya durante el último tercio del XVIII y comienzos del XIX existe un sustrato filosófico-naturalista que podría haber facultado la proyección museográfica de la condición corpórea del ser humano. Si esto no ocurre, o no de forma claramente reconocible ni generalizada, quizás sea porque entran en juego otros factores. Se podría argumentar, por ejemplo, que siendo tan rico y variado el repertorio de especímenes que ofrece la naturaleza (sobre todo los llegados desde ultramar), la presencia de lo humano en estas colecciones resultaría escasamente atractiva, debido a su relativa uniformidad. Una opción sugerente podría haber sido mostrar el repertorio de "razas" humanas entonces conocido mediante la presentación de individuos disecados. Sin embargo, ni la taxidermia es un recurso fácil de aplicar al cuerpo humano ni la propia idea de disecar personas tuvo nunca buena prensa entre los naturalistas ${ }^{9}$; tampoco la de preservar cabezas o cuerpos completos en alcohol. Y recurrir a un mero despliegue de huesos, cráneos o esqueletos no parece que se considere entonces ni atractivo ni relevante; será tiempo después cuando se le encuentre una muy racista utilidad.
Por otra parte, también es posible que los responsables de estos museos no conciban incluir al "hombre" entre el amplio repertorio de especímenes del reino animal que exhiben (y estudian), por considerarlo algo aparte, una creación absolutamente singular del Todopoderoso. Sea como fuere, la consecuencia última de ese escaso interés es que todo lo concerniente al ser humano como ente físico se convierte durante más de un siglo en territorio administrado y exhibido de forma mayoritaria por los gabinetes y museos anatómicos, hasta que a partir del último tercio del XIX acaban siendo en buena medida sustituidos o desplazados por los nuevos y potentes museos de antropología.

\section{MUSEOS ANATÓMICOS Y ANTROPOLÓGICOS EN LA ESPAÑA DEL SIGLO XIX}

Aunque durante las primeras décadas del siglo XVII (y aún después) la presencia de restos humanos en las cámaras de curiosidades es limitada y apenas explícita, por esos mismos años se pueden contemplar ya esqueletos humanos auténticos en algunos teatros anatómicos (salas de disección) y en los gabinetes anexos de ciertos hospitales y escuelas de cirugía, como se observa en el conocido grabado del teatro anatómico de la Universidad de Leiden, de $1610^{10}$. Con desigual proyección, dependiendo del progreso de los estudios anatómicos y de la práctica disectora en los diferentes países, las colecciones de restos humanos preservados se extienden gracias a destacadas iniciativas particulares -como la del holandés Frederik Ruysch (1638-1731) - y sobre todo a los renovados gabinetes anatómicos de las escuelas de cirugía y a sus continuadores, los museos anatómicos de las nuevas facultades de medicina, que se desarrollan de forma imparable durante el último tercio del XVIII y gran parte del XIX (Alberti y Hallam, 2013; Hallam, 2016). Con el propósito de ofrecer a los estudiantes un acercamiento empírico al conocimiento de la anatomía humana (normal y patológica), todos estos centros exhiben una numerosa y variada tipología de restos humanos, tanto huesos, cráneos y esqueletos completos como preparaciones anatómicas, secas o conservadas en alcohol. También es habitual el despliegue de vaciados realizados en diferentes materiales y de piezas mucho más impactantes: esculturas en cera de secciones corporales, de órganos internos y de cuerpos completos de sobrios varones o de lánguidas mujeres, las famosas venus anatómicas. 
Es obvio que la contemplación de los restos humanos auténticos exhibidos en todas estas colecciones habría de generar sensaciones y reacciones contradictorias: curiosidad, excitación, morbo, angustia, incluso goce estético. Sin embargo, dado que en la mayoría de los casos el acceso queda restringido a especialistas y estudiantes, su proyección pública resulta muy limitada. Pues bien, precisamente esta circunstancia se convierte en acicate para que ciertos personajes, vinculados o no con el ámbito científico, pongan en marcha unas creaciones que ofrecen a la vista del público aquello que le ocultan los museos anatómicos académicos. Me refiero a los museos anatómicos comerciales (Sappol, 2004; Bates, 2008; Podgorny, 2013; Stephens, 2013), la mayoría itinerantes, que triunfan en buena parte de Europa y América entre 1830 y 1930 y que son tan solo un elemento más de un amplio repertorio de prácticas exhibidoras que abarca desde los panoramas, los pasajes comerciales y las barracas de feria hasta las inmensas exposiciones internacionales de la segunda mitad del $\mathrm{XIX}$ y el primer tercio del $\mathrm{XX}^{11}$. Estos novedosos museos anatómicos comerciales ofrecen unos contenidos mucho más impactantes y sugerentes que los gabinetes del XVIII, con un repertorio similar, aunque no idéntico, al de los museos académicos. También varían las estrategias publicitarias y el régimen de exhibición, que resulta mucho más llamativo y espectacular. Pueden mostrar, por ejemplo, pieles humanas curtidas e incluso cuerpos taxidermizados, que no suelen guardar los museos académicos, aunque se exhiben en espacios restringidos (de acceso exclusivo para varones adultos previo pago de una entrada adicional), donde también se disponen las piezas que representan el aparato genital (masculino y femenino) o las terribles consecuencias de las enfermedades venéreas.

En España hay que esperar hasta la segunda mitad del XVIII para documentar gabinetes anatómicos (académicos) dignos de tal denominación. Es entonces cuando los nuevos ideales de la monarquía ilustrada renuevan e impulsan la enseñanza de la anatomía y la cirugía, gracias a la creación de una nueva institución médico-docente: los Reales Colegios de Cirugía. El primero en salir adelante es el de Cádiz, fundado en 1748 y destinado a la formación de los cirujanos de la Armada. Le sigue el de Barcelona, en 1760, para cirujanos del Ejército. El tercero y último es el Real Colegio de Cirugía de San Carlos, que se instala en Madrid en 1787, destinado ya a la formación de cirujanos civiles. Sabemos que los dos primeros dispo- nen de gabinetes anatómicos, pero es el de San Carlos el que alcanza mayor desarrollo y prestigio gracias a la diligencia de su primer director, el catalán Antonio Gimbernat (1734-1816), pues pronto cuenta (entre otros materiales de estudio) con una relevante colección de figuras anatómicas en cera, gran parte de ellas elaboradas por el español Juan Cháez y el italiano Luigi Franceschi, bajo la dirección de Ignacio Lacaba, maestro disector del Real Colegio y, desde 1795, catedrático de anatomía del mismo (Morente Parra, 2016).

Además de las impresionantes figuras de cera instaladas en sus inicios, a lo largo del siglo XIX el gabinete madrileño incorpora gran número de vaciados, además de huesos, esqueletos y preparaciones de restos humanos ${ }^{12}$. Mediada la centuria, y ya con la denominación oficial de Museo Anatómico, se encuentra relativamente bien instalado en el edificio de la nueva Facultad de Medicina, en la madrileña calle de Atocha ${ }^{13}$. Entre 1857 y 1868, siendo su director Pedro González Velasco (1815-1882), crece de forma considerable; de hecho, el propio doctor es artífice de buena parte de las preparaciones y vaciados que entonces se suman a las colecciones ${ }^{14}$. Además, desde tiempo atrás el centro dispone de ciertas piezas de cualidad singular que, sin resultar demasiado útiles en el ámbito formativo, otorgan prestancia a una institución de estas características: dos esqueletos de gigantes, ${ }^{15}$ una tsantsa (cabeza reducida por los shuar o jíbaros) y sendas momias de origen incierto (López de la Vega, 1871-72). En principio, el acceso al museo está reservado al personal docente y a los estudiantes, pero es muy probable que el público lo pueda visitar bajo ciertas condiciones. Así está documentado al menos desde la década de 1860 , siendo entonces necesario el permiso expreso del decano ${ }^{16}$. Lamentablemente, no conozco documentación alguna que nos informe sobre la condición y las reacciones de los visitantes.

Aunque el museo de la facultad madrileña logra salir adelante, la inestable coyuntura sociopolítica que vive el país incide de forma muy negativa en el progreso de la medicina y la anatomía durante la primera mitad del siglo XIX. Obviamente, no es un ambiente propicio para la formación de colecciones anatómicas privadas. De hecho, solo puedo citar una anterior a los años 50: el "Museo del doctor Soler", instalado en Barcelona entre mediados de la década de 1820 y finales de la de 1840 por José Soler, catedrático del Real Colegio de Medicina y Cirugía de 
Barcelona. Aunque sabemos poco de sus contenidos, Madoz (1846, pp. 515-516) anota en su diccionario geográfico que guarda "muchas figuras hechas de cera por el célebre Chiapi", "colecciones de fetos de todas edades en espíritu de vino" y muy variadas curiosidades ${ }^{17}$. Lamentablemente, ya por entonces se encuentra en un estado de completo abandono.

Si apenas existen colecciones privadas durante la primera mitad del XIX, no ha de extrañar que tampoco abunden los museos anatómicos comerciales. Se ha documentado algún gabinete de cera barcelonés que exhibe piezas anatómicas en la década de 1840, aunque parece que no cuenta con preparaciones (Pardo Tomás y Zarzoso Orellana, 2017). Estos centros, siempre de carácter itinerante, son algo más frecuentes durante la segunda mitad de la centuria, aunque los que he podido localizar parecen de origen foráneo: Museo Anatómico de Teodoro Petersen (1858), Museo Antropológico, Anatómico y Etnológico de M. A. Neger (1868), Museo Harkopff (1874), Museo Anatómico y Etnológico de Enrique Dessort (1878), Museo Anatómico de O. Thiele (1885) y Museo Anatómico y Antropológico de W. Dicman-Pezon $(1886)^{18}$. Junto a materiales etnográficos y modelos de tipos étnicos, todos exhiben vaciados, láminas, maniquís, ceras anatómicas y, ahora sí, restos humanos auténticos ${ }^{19}$. Al margen de estas exposiciones itinerantes, sólo conozco un museo comercial estable fundado por un ciudadano español durante aquellos años: el "Gran Museo de Historia Natural, de Anatomía comparada, Etnología, Antropología, Anatomía normal y patológica", abierto en Barcelona, en 1888, por el taxidermista catalán Francesc D’Assís Darder Llimona (1851-1918). Su función principal es la exhibición y venta de animales disecados, pero también cuenta con cráneos y esqueletos humanos, fetos preservados en alcohol, vaciados y preparaciones anatómicas, algunas pieles humanas curtidas y el famoso "Negro de Banyoles", sobre el que luego volverée ${ }^{20}$.

Más allá de los casos citados, debo insistir en que el ambiente que se respira en la España de mediados del XIX no resulta propicio para la formación de museos anatómicos, menos aún si sus pretensiones son más académicas que comerciales. En una situación así, tiene especial mérito la puesta en marcha de un atrevido proyecto museístico privado que culmina casi un cuarto de siglo más tarde, en 1875. Me refiero a la inauguración, en 1854, del primer Museo Anatómico (esta es su denominación) del doctor Pedro González Velasco.
A semejanza de otros cirujanos coleccionistas europeos, Velasco instala el museo en su domicilio particular, en el número 135 (hoy 107) de la calle de Atocha, justo enfrente de la Facultad de Medicina madrileña (Sánchez Gómez, 2015). Aunque de modestas dimensiones, reúne una destacada colección de cráneos y huesos (normales y patológicos), vaciados y preparaciones de deformidades y enfermedades diversas (incluida la sífilis), fetos en alcohol y maniquíes para la práctica en la colocación de vendajes. También incluye materiales que entonces son habituales en los museos anatómicos: la sección de "anatomía comparada", con esqueletos, vísceras y animales disecados. Finalmente, completan la colección curiosidades diversas y una momia vendada (al estilo egipcio), preparada por el propio Velasco. EI carácter científico-docente de todo este despliegue se refuerza con un microscopio, instrumental médico (antiguo y moderno), un pequeño laboratorio y una biblioteca. Todos estos complementos prácticos tienen su razón de ser en el hecho de que el museo no es un mero lugar de contemplación: es un espacio de estudio, un elemento esencial en la oferta docente privada de su propietario, que es ciertamente exitosa.

Por supuesto, los principales usuarios del museo son los alumnos, pero también tienen acceso los pacientes que visitan su consulta, personajes públicos relevantes y seguramente ciudadanos que cuentan con permiso del doctor, aunque no parece que exista un horario de acceso predeterminado. En muy pocos años, la singularidad del museo y las notas que ofrece ocasionalmente la prensa madrileña lo hacen relativamente conocido entre la ciudadanía. Al mismo tiempo, su apertura es un acicate para la puesta en marcha de otros centros de orientación similar en la ciudad de Madrid. Es el caso del Museo Sifilográfico (sobre los estragos causados por la sífilis) que el médico José Díaz Benito (amigo y antiguo socio empresarial de Velasco) instala en su domicilio, en 1860. Poco antes el mismo Díaz Benito había puesto en marcha el Museo Anatómico del Hospital Militar, aunque será Cesáreo Fernández de Losada quien durante las décadas de 1870 y 1880 lo dinamice, organizando una importante colección de reproducciones anatómicas y piezas reales preservadas que, lamentablemente, desaparece en el incendio que destruye el edificio en 1889 (Azcárate Luxán, 2006) 21.

Mientras tanto, como el afán coleccionista de Velasco no cesa y su muy saneada economía se lo per- 
mite, la angustiosa necesidad de espacio le fuerza a construir una nueva residencia en la misma calle de Atocha (en el número 90, hoy el 92) y a instalar allí, a finales de 1864, su nuevo Museo Anatómico-Patológico (Sánchez Gómez, 2015). Aunque la exposición ocupa solo 150 metros cuadrados, la tipología de las piezas y su distribución generan un ambiente que combina academicismo y teatralidad de forma tal que sin duda habría de impresionar profundamente a los visitantes ${ }^{22}$. Sus contenidos son similares a los del museo anterior, aunque incrementados en número. Eso sí, el nuevo centro goza de una proyección pública mucho más intensa, circunstancia impulsada por las constantes notas que publica tanto la prensa médica como la generalista sobre la incorporación de nuevas piezas. Así ocurre, por ejemplo, con la aceptación por parte de Velasco de la donación más singular de cuantas recibe: el cadáver momificado de una niña, hija de un médico conocido suyo (Manuel Taín), exhumado a los seis años de su muerte y que, por causas naturales, se había preservado de forma solo medianamente aceptable. El padre considera que el cuerpo de su hija es digno de ser conservado y exhibido, y Velasco se muestra conforme. Bien, es verdad que otros cuerpos momificados se exhibieron antes y se continuarán exhibiendo después, pero este caso es especialmente macabro y ciertamente la "pieza" nada aporta al progreso de la anatomía o la antropología (Sánchez Gómez, 2017b, pp. 113-118).

El empeño coleccionista de Velasco acaba convirtiéndose en una verdadera obsesión, que casi le arruina. Pero de no haber sido por ese peculiar carácter (y por sus dineros) nunca hubiera levantado su postrera y más grandiosa creación: el extraordinario Museo Antropológico, que inaugura el rey Alfonso XII en abril de 1875. Para este tercer y último proyecto museístico su creador articula un modelo diferente al de los dos anteriores: ya no despliega sus colecciones en una sala de su domicilio particular, ahora es su propia casa la que se instala como anexo de un gran museo. El llamativo edificio de fachada neoclásica, que aún podemos contemplar como sede del Museo Nacional de Antropología en Madrid, es seguramente el de mayor empaque levantado por un particular para albergar un museo de anatomía en la Europa del siglo XIX. Su interior, transformado y menguado tras la reforma realizada en la década de 1940, en tiempos de Velasco habría de impactar por la amplitud y el apabullante despliegue de armarios que entonces recorre los muros del salón principal y la galería superior que lo circunda, características que se repiten en el denominado salón pequeño, aunque a menor escala (Sánchez Gómez, 2014).

Por lo que se refiere a las colecciones, es cierto que existen notables desajustes entre las distintas secciones; de hecho, algunas nunca llegan a ser adecuadamente estructuradas y otras, que teóricamente lo están, resultan fallidas. Hay piezas que remiten a un coleccionismo de lo absurdo. Su discípulo y principal biógrafo no tiene reparo en reconocer que "un espíritu delicado o exigente hubiera eliminado numerosos ejemplares como frivolidades impropias de figurar en un Museo serio" (Pulido, 1894, p. 92). También admite que, comparadas con las nuevas "reproducciones plásticas", las piezas elaboradas en escayola por Velasco resultan "barrocas, pesadas, y atestiguan un periodo primitivo de semejante industria", y que, gracias al formol, las preparaciones húmedas se conservan mejor y resultan mucho más vistosas e instructivas que en tiempos de su maestro. Pero, dicho esto, no podemos olvidar que el gran salón principal (y su galería) es precisamente el espacio mejor estructurado del centro, pues ofrece muy interesantes y organizados materiales sobre la anatomía humana y sus principales patologías. De hecho, el mismo Pulido destaca la relevancia de la sección de músculos y vasos sanguíneos, las colecciones osteológicas, craneológicas, embriológicas y teratológicas que, según nos dice, superan a la mayoría de las conservadas en instituciones europeas contemporáneas. Además, y quizás con el objetivo de que en el futuro su creación se convirtiera en un verdadero museo antropológico (pues, pese a su denominación formal, continúa siendo un museo de anatomía), Velasco reúne también interesantes materiales etnográficos de España y de muy diversa procedencia que, lamentablemente, guarda sin orden alguno en dos pequeñas salas no accesibles a los visitantes.

Mientras se mantiene abierto en su formato original, hasta la muerte de su fundador, me atrevo a decir que el Museo Antropológico exhibe el más extenso y variado repertorio de restos humanos preservados que se haya mostrado nunca de forma pública en España. No puedo confirmar en qué medida contribuye a popularizar el conocimiento de la anatomía humana y sus patologías, pero por las referencias de prensa documentadas da la impresión de que al menos una parte de los visitantes valora el interés científico y más aún personal (relacionado con su propia salud) de lo que allí se contempla, aunque seguro que otros muchos salen del museo gozosamente ho- 
rrorizados. Y sí, la morbosa atracción que ejerce está justificada, pues el museo no solo exhibe cráneos (dispone de casi medio millar, incluido el de algún criminal), esqueletos completos, fetos auténticos normales y teratológicos, órganos internos y porciones de cuerpos preservadas, algunas con horrendas patologías; también despliega un par de momias (la niña recibida 1873 y otra más de origen andino), una tsant$s a$, siete cabezas momificadas de presunto origen egipcio, el maniquí de "un árabe", modelos (no piezas reales) de cabezas de "las principales razas humanas" e incluso una colección de "pieles curtidas" con tatuajes, que por esas fechas, y durante tiempo después, interesan sobremanera a los antropólogos y luego a los criminólogos que estudian el mundo del hampa y la criminalidad ${ }^{23}$. Pero la "pieza estrella" del museo es otra, aún más morbosa que las mencionadas: la versión por triplicado de un personaje que había caminado (aunque poco) por las calles de Madrid solo unas semanas antes de ingresar en el centro: Agustín Luengo Capilla (1840-1875), conocido como "el Gigante Extremeño". Y la versión es triple porque Velasco muestra el vaciado del cadáver, el esqueleto y, aquí radica lo más extraordinario del caso, la piel montada y vestida con su indumentaria habitual; es decir, exhibe a Luengo taxidermizado ${ }^{24}$.

Ya he anotado que disecar y exponer cuerpos humanos no ha sido nunca una práctica habitual, pero tampoco se puede considerar algo absolutamente extraordinario ${ }^{25}$. Además, los casos documentados involucran tanto a individuos considerados exóticos o "salvajes" como a gentes de origen "doméstico", si bien es cierto que los primeros son seleccionados por su singularidad étnica y los segundos por presentar alguna patología deformante. Aunque hoy puede resultar chocante, debemos asumir que, junto con los factores racistas y clasistas que entran en juego, la idea de preservar y mostrar un cuerpo humano completo entra en la mente de algunos cirujanos y antropólogos (y de amplios sectores de la ciudadanía) de una forma que casi podríamos considerar "natural", aceptada como parte de las iniciativas que contribuyen al progreso de la ciencia. No obstante, hemos de reconocer que el caso de Luengo es muy especial, pues la pieza en cuestión tiene nombre y apellidos. El visitante que en tiempos de Velasco se sitúa frente a la figura con la piel del desdichado extremeño contempla unos restos humanos con una fisonomía en buena medida reconocible, pese a las alteraciones producidas durante su tratamiento $\mathrm{y}$ montaje. Pese a todo, y aunque la experiencia visual quizás resulta perturbadora, con su exhibición Velasco ofrece una prueba irrefutable de la existencia real de los gigantes humanos, al menos de cierta categoría de gigantes, si bien es verdad que en ningún momento argumenta las circunstancias que explican tan desmesurado crecimiento. Pero el asunto de las antropotaxidermias velasqueñas no termina aquí ${ }^{26}$.

En efecto, el 26 de abril de 1879 el diario La Iberia informa de una nueva y singular pieza que se puede contemplar en el museo: "la Venus, una hotentota joven". Aunque no existe ninguna documentación al respecto, Pulido Fernández $(1894$, p. 87) nos ofrece una interesante imagen del salón grande en la que se observa una figura femenina que con total seguridad se corresponde con este personaje. A pesar de la muy escasa calidad de la reproducción, podemos comprobar que no es una copia de la famosa "Venus hotentote", la joven khoikhoi (Saartjie Baartman) que es exhibida en Europa a comienzos del siglo XIX, muere poco después, es diseccionada y disecada por $\mathrm{Cu}$ vier, nuevamente exhibida (genitales, cerebro, esqueleto y moulage) en el Museo del Hombre parisino hasta 1974 y finalmente retornados sus restos a la República de Sudáfrica en 2002 (Blanckaert, 2013). Y no parece una copia porque, entre otras diferencias menos evidentes, el vaciado que realiza Cuvier tiene los brazos bajados, mientras que la figura de Velasco muestra el izquierdo erguido y sujeta un bastón. ¿Se trata de un simple modelo en yeso, o cartón piedra, o es una mujer khoikhoi real, disecada ${ }^{27}$ El inventario redactado de forma previa a la adquisición del museo por el Estado, en 1887, indica que en el salón grande se exhiben "dos individuos de la raza negra, hombre y mujer, disecados con su piel natural"28. Como resulta muy improbable que los cinco catedráticos encargados de elaborarlo (entre los que se cuenta el destacado anatomista y antropólogo Federico Olóriz Aguilera) no sepan distinguir una figura en yeso de otra cubierta con su propia piel, deberíamos asumir que, efectivamente, la pieza en cuestión es una mujer khoikhoi taxidermizada que, además, se acompaña de una pareja masculina de idéntica cualidad. Desgraciadamente, no hay ninguna otra información que lo confirme. También surgen dudas en torno al varón, pues la única figura que en algunos textos se califica como "un negro" es una que se distingue con claridad en las fotografías del museo tomadas por Laurent tras su inauguración, que no representa a un khoikhoi y cuyos rasgos y textura hacen pensar que se trata simplemente de un maniquí (Sánchez Gómez, 2014, p. 272). Pese a todo, y aunque no puedo asegurar que 
tales "individuos de la raza negra" fueran realmente seres humanos "con su piel natural", es evidente que podrían haberlo sido y que, lo fueran o no, su exhibición no genera entonces escándalo alguno.

Velasco muere en octubre de 1882 . Aunque durante varias décadas su gran creación continúa siendo conocida como "el Museo del doctor Velasco" y pese a que es adquirido por el Estado en 1888, nadie se plantea su continuidad. Tras intensas discusiones se adueñan del edificio, y de las piezas que les interesan, la Facultad de Ciencias (asociada al Museo de Ciencias Naturales) y la Facultad de Medicina de la Universidad de Madrid. Las colecciones sobrantes se reparten entre varias instituciones universitarias y museísticas del país. A finales de 1895 la esencia del museo original ha sido por completo aniquilada. Allí se instala ese mismo año la Sección de Antropología del Museo de Ciencias Naturales, que dirigía desde 1883 Manuel Antón y Ferrándiz. En 1910 la sección se independiza para dar origen al Museo de Antropología, Etnografía y Prehistoria, vinculado a la Junta para Ampliación de Estudios e Investigaciones Científicas. Antón se convierte en su primer director. A partir de este momento, se intensifica el proceso de cambio que había arrancado en 1895 y que transforma por completo el modelo de proyección museográfica de lo humano, que pasa del ámbito de la medicina y la anatomía al de las ciencias naturales, más en concreto al de la antropología física. Los moldes y las preparaciones anatómicas desaparecen. Se mantiene la inmensa mayoría de los cráneos y esqueletos, pero ya no preocupan las anatomías normales ni las patológicas, tampoco las monstruosidades humanas. Ahora se impone la moderna antropología física, que acaba de acceder a las cátedras universitarias y que se interesa por la morfología del hombre moderno, por la de nuestros antepasados más remotos, por la del individuo vinculado con la criminalidad y, por supuesto, por la "diversidad racial". Asumiendo la triple orientación académica de su denominación, el nuevo museo recibe algunos cráneos y otros restos óseos procedentes de excavaciones arqueológicas, aunque los restos humanos más relevantes que allí asientan sus lares llevaban tiempo en España. Me refiero a las momias de Chiu Chiu (hoy en Chile) traídas por la Expedición del Pacífico de 1862-1866 y a la famosa momia guanche ingresada en el antiguo Real Gabinete de Historia Natural en $1776^{29}$. No obstante, y pese al interés que entonces existe por las "razas" exóticas, las limitaciones de espacio, presupuesto y personal, unidas sin duda a los intereses de su direc- tor, no permiten que el nuevo Museo de Antropología articule colecciones craneológicas relevantes. Curiosamente, es un catedrático de anatomía, el citado Federico Olóriz, quien por esas mismas fechas está reuniendo la mayor colección de cráneos organizada en España y una de las más destacadas de Europa (supera los 2.200 ejemplares), pero lo hace en la Facultad de Medicina madrileña, donde aún se conserva, aunque disgregada. He de advertir, sin embargo, que la inmensa mayoría de las piezas es de procedencia peninsular, pues precisamente a Olóriz no le interesan los mundos exóticos sino el estudio del pueblo español, tanto en el ámbito de la "normalidad" como en el de la criminalidad. El nuevo Museo Antropológico opta por una forma más vistosa y, en principio, menos morbosa de mostrar la diversidad racial: la exhibición de máscaras mortuorias y maniquís etnográficos, figuras que acaban ocupando la mayor parte del salón central hasta su desaparición en la reforma de los años 40 .

Vamos llegando al final. Pero, antes de terminar, aún debo hacer referencia a un último caso de antropotaxidermia que a punto estuvo de sumarse a las colecciones del Museo Antropológico. Es un asunto muy singular, que se gesta en la primera mitad del siglo XIX, se proyecta en un inicial contexto museográfico en la década de 1880 , se exhibe al público durante casi un siglo y acaba estallando en los medios de comunicación a comienzos de la década de 1990. Me refiero, obviamente, al "Negro de Banyoles" ${ }^{30}$.

El cadáver del infortunado miembro de la etnia san (bosquimano) había sido expoliado de su sepultura en tierras sudafricanas por los hermanos Verreaux (JulesPierre, Jean-Baptiste y Joseph-Alexis) en 1830. Los personajes en cuestión eran taxidermistas y comerciantes de piezas de historia natural radicados en París, donde llevan la figura disecada y la exhiben con el objeto de venderla, sin conseguirlo. Medio siglo más tarde, en 1883, los tres hermanos ya han fallecido, aunque el negocio de taxidermia sigue adelante en manos de un descendiente: V. E. Verreaux. Ese mismo año, Manuel Antón Ferrándiz pasa una temporada en París, en el Museo de Historia Natural. En la capital francesa entra en contacto con el citado personaje y sin duda contempla el varón san disecado. En su charla con el taxidermista quizás hace alguna observación sobre la pieza. Muy probablemente el asunto no pasa de un amable intercambio de palabras, pero Verreaux atisba un negocio prometedor, la oportunidad de deshacerse a buen precio del "bechuana", como lo deno- 
mina. De regreso en Madrid, Antón recibe una curiosa carta del francés ${ }^{31}$. Sus palabras demuestran que Antón no le hizo oferta alguna de compra y que tampoco debió de mostrar mucho interés por la pieza. Sin embargo, el ansia negociadora del parisino le hace pensar, como dice en su escrito, que tiene "chance de traiter l'affaire de mon Bechuanas" con el Museo de Ciencias Naturales de Madrid, donde Antón acaba de poner en marcha la Sección de Antropología. Allí podría ocupar, según Verreaux, "une belle place". También es hermoso el precio que pone a la figura: nada menos que 10.000 francos. El lote está formado por el "bechuana", la vitrina de cristal donde se guarda y un llamativo complemento: "la tête montée du Mozambique qui est encore une pièce d'une préparation remarquable"; es decir, la cabeza real disecada de un negro mozambiqueño. No se conserva copia de la respuesta de Antón; quizás no le responde. El asunto se olvida.

Sin embargo, solo cuatro años más tarde, en 1887, el "bechuana" reaparece en una exposición comercial organizada en Barcelona por el taxidermista catalán Francesc Darder, su nuevo dueño, quien como vimos abre al año siguiente su museo de historia natural. También Darder quiere hacer negocio con el africano, pero ya sea por lo desorbitado del precio (7.500 pesetas) o por su singular tipología, nadie lo adquiere ${ }^{32}$. Tiempo después, en 1916, tras casi tres décadas de exhibición en su museo, su propietario dona la figura y el resto de sus colecciones al Ayuntamiento de Banyoles. Con ellas se forma el nuevo Museo Darder. Allí se muestra "el Negro" durante 75 años más, junto con otros restos humanos, sin dar motivo al más mínimo comentario..., hasta que la actividad publicista generada de forma previa a los Juegos Olímpicos de Barcelona remueve el fango. La denuncia del caso, junto a la exigencia de que los restos del africano sean devueltos a su lugar de origen, la presenta en 1991 el abogado español, de origen haitiano, Alphonse Arcelin. El asunto salta de forma inmediata a los medios de comunicación, tanto nacionales como internacionales. Se organiza un enorme escándalo. Tras casi una década de denuncias y resistencias, la figura se retira de la exposición en el año 2000. Antes de su conclusión, el relato conecta de nuevo con el antiguo museo de Velasco, ahora Museo Nacional de Antropología, pues es aquí donde se retira la piel, el cráneo y los pocos huesos auténticos que conserva la figura. Son los únicos materiales que se envían a tierras africanas. A finales de ese mismo año los restos son inhumados con honores de Estado en Gaborone, la capital de Botsuana.

\section{RECAPITULACIÓN}

El objetivo del artículo ha sido reflexionar sobre un hecho que en principio podría considerarse singular y un tanto macabro: la exhibición en contextos museológicos de huesos y restos humanos preservados. Se ha presentado un marco de referencia genérico al que ha seguido el comentario de ciertos casos documentados en museos españoles. Hemos comprobado que su presencia es muy limitada en las cámaras renacentistas y en los gabinetes barrocos. También constatamos que, ya durante la segunda mitad del XVIII y comienzos del XIX, los primeros museos de historia natural no asumen de forma decidida la exhibición del ser humano como ente físico, ni en su esencia corpórea singularizada ni desde la perspectiva de su diversidad "racial". En esta coyuntura, los gabinetes anatómicos afrontan esa tarea de manera entusiasta, aunque lo hacen, obviamente, desde una perspectiva médica, no naturalista. Durante la mayor parte del XIX la obsesión por coleccionar y mostrar elementos anatómicos no se detiene, justificándose incluso la preservación y exhibición de cuerpos completos, taxidermizados, sobre todo de individuos de origen nacional con anatomías singulares, pero también de algún personaje exótico o pretendidamente "salvaje". Luego, desde finales de siglo, los museos anatómicos pierden relevancia, más aún en España. Por esas fechas, los nuevos museos antropológicos se adueñan de la exhibición de cuerpos humanos, aunque optan de forma mayoritaria por mostrar la diversidad étnica mediante figuras y grupos escultóricos, no a través de cuerpos preservados, si bien es cierto que muchos conservan y hasta acrecientan sus colecciones de cráneos. Algunos mantienen en sus vitrinas restos humanos o cuerpos taxidermizados que, ya en el siglo XXI, acaban siendo devueltos a sus lugares de origen. Lamentablemente, tras los fastos y la pose fotográfica de las autoridades, el asunto y las mismas sepulturas donde fueron depositados los restos terminan en el olvido. Actualmente, los protocolos de actuación con restos humanos limitan de forma notable su conservación y exhibición pública, al tiempo que recomiendan su restitución en determinados casos y circunstancias. Sin embargo, todo ello no ha sido obstáculo para que se desarrollen nuevas formas de exhibición de lo humano, entre las que sin duda destaca el proyecto Bodyworlds, del alemán Gunther von Hagens, que transmuta y transporta el modelo de museo anatómico decimonónico a una inquietante y controvertida dimensión. 


\section{AGRADECIMIENTOS}

Trabajo realizado en el proyecto de investigación: "El coleccionismo científico y las representaciones museográficas de la Naturaleza y de la Humanidad", financiado por la Agencia Estatal de Investigación del Gobierno de España y el Fondo Europeo de Desarrollo regional (HAR2016-75331-P.AEI/FEDER, UE). Agradez- co a Carmen Ortiz García sus observaciones sobre el original de este artículo y a los dos evaluadores anónimos su detallada lectura crítica, que ha permitido mejorar, en la medida de lo posible, la versión final del texto.

\section{NOTAS}

1 La atracción que ejerce la representación de cuerpos humanos muertos, tanto en contextos artísticos como vinculados con los estudios anatómicos, se comprueba en el catálogo de la magnífica exposición La invención del cuerpo, presentada recientemente en el Museo Nacional de Escultura de Valladolid y el Museo San Telmo de San Sebastián (Bolaños, 2018). Insisto, no obstante, en que los materiales mostrados son representaciones pictóricas o escultóricas, no huesos o restos humanos auténticos preservados.

2 Algún gabinete renacentista o barroco exhibe huesos de grandes mamíferos (antiguos o modernos) asumiendo su condición humana excepcional, es decir, considerándolos huesos de gigantes humanos. Sin embargo, pienso que esta identificación con presuntos gigantes antiguos desvincula de forma notable tales piezas de los restos auténticos de humanos contemporáneos.

3 Por supuesto, se podría argumentar que existen individuos a quienes seduce la presunta belleza de los cuerpos humanos muertos, al menos durante los momentos inmediatamente posteriores a la defunción. No obstante, considero que esta circunstancia no anula la validez del argumento presentado.

4 La bibliografía sobre el coleccionismo durante el Renacimiento y el Barroco es muy abundante. Citaré solo los trabajos de Schlosser (1988), Impey y MacGregor (2017) y MacGregor (2007).

5 Por supuesto, existen notabilísimas excepciones. No me refiero a osarios o catacumbas, sino a casos como los de los esqueletos ricamente decorados de la basílica alemana de Waldsassen y otros similares, que resultan ciertamente espectaculares.

6 Sobre el estudio, la representación gráfica y la exhibición de esqueletos humanos entre 1500 y 1800 , con una intencionalidad esencialmente anatómica, véase Guerrini (2016). También son interesantes las páginas que dedica Pimentel (2010, pp. 158-169) a las representaciones de huesos y esqueletos humanos ( $y$ animales), que trae a colación al comentar los grabados del famoso megaterio que estudia en su libro.

7 Sobre las cámaras de maravillas y las cámaras relicario en España continúa siendo esencial la obra de Morán Turina y Checa Cremades (1985). También es útil la más reciente síntesis de Sánchez Almazán (2013).
8 Se observa en el famoso grabado del gabinete que se incluye en el catálogo del museo publicado en 1678 (Sepibus, 1678).

9 Según indicaciones del taxidermista Salvador Pérez, los problemas que plantea la piel humana para ser disecada no se deben tanto a su escaso grosor como a la ausencia de vello abundante o de plumas, elementos que permiten manejar otras pieles tanto o más delgadas sin demasiadas dificultades.

10 Se ofrece una buena copia digital de este grabado en https://en.wikipedia.org/wiki/Leiden_anatomical_theatre.

11 Estas prácticas incluyen la modalidad más impactante (y muchas veces, pero no siempre, degradante) de exhibición de humanos: el despliegue de seres humanos vivos, ya sea de forma individual o grupal, y ya se trate de "gigantes", de "enanos", de personas con patologías deformantes o de gentes procedentes de culturas exóticas o pretendidamente "salvajes" (Sánchez Gómez, 2013).

12 Muchas de estas piezas se conservan en el Museo de Anatomía "Javier Puerta", en la Facultad de Medicina de la Universidad Complutense de Madrid, en unas instalaciones que, pese a la dedicación de su director (el profesor Fermín Viejo), distan mucho de ser las adecuadas desde una perspectiva museográfica. El interés de los responsables del antiguo gabinete por coleccionar (no tanto estudiar) restos humanos los induce incluso a intentar taxidermizar el cadáver de Pedro Antonio Cano, un gigante procedente del Virreinato de Nueva Granada que se presenta a Carlos IV en 1792 y que fallece en Madrid en 1804. Aunque fracasan en su intento de preservar la piel, guardan las vísceras y montan su esqueleto, que aún hoy se puede contemplar en el citado museo de anatomía (Sánchez Gómez, 2018).

13 Debo señalar que solo comentaré los contenidos del museo anatómico de la Facultad de Medicina madrileña. Por supuesto, existen centros similares en las demás facultades del país (y en toda Europa), que han tenido un desarrollo dispar. Además, durante el siglo XIX algunos institutos de enseñanza media disponen de huesos humanos en sus colecciones didácticas, aunque es mucho más habitual la presencia de modelos anatómicos artificiales. Concluida la redacción de este artículo, he accedido a un interesante trabajo que repasa de forma sumaria las colecciones de anatomía normal y patológica creadas en las universidades y en algunos hospitales españoles durante el siglo XIX y la primera mitad del XX (Mariño, Meseguer y Baquero, 2018). 
14 En realidad, las colecciones citadas pertenecen a dos secciones diferentes del museo, aunque también se habla en ocasiones de varios museos anatómicos dentro de la facultad. Las mencionadas corresponden al "Museo anatómico natural" (huesos y preparaciones reales) y al "Museo anatómico artificial" (vaciados). Aunque no puedo establecer el momento de su creación, al menos desde la década de 1870 existe una sección o "Museo de instrumentos, apósitos y aparatos ortopédicos", un "Museo iconográfico" (láminas) y otro más vinculado al Laboratorio de Toxicología y Medicina Legal (Castro, 1875).

15 El de mayor altura pertenece al citado Pedro Antonio Cano. Se desconoce la procedencia del segundo.

16 La Soberanía Nacional, 25 de marzo de 1865 y La Correspondencia de España, 23 de febrero de 1884.

17 El escultor citado es el italiano Giuseppe Chiappi, que durante la década de 1820 exhibe de forma itinerante por España una colección propia de ceras anatómicas, algunas de las cuales guarda hoy el Museu d'Història de la Medicina de Catalunya. Agradezco a Alfons Zarzoso, su conservador, la información proporcionada sobre este y otros temas de historia de la medicina.

18 El año mencionado se refiere al de edición del catálogo del que tomo el nombre.

19 Pardo Tomás y Zarzoso Orellana (2017) repasan la "geografía urbana" de los museos anatómicos de Barcelona desde finales del siglo XVIII hasta la década de 1930. Ambos autores dedican otro trabajo a la azarosa historia de uno de los últimos museos anatómicos comerciales de la ciudad, el Museo Roca (Zarzoso y Pardo-Tomás, 2016).

20 Sobre el Museo Darder y la biografía de su creador son muy recomendables sendas entradas incluidas en el blog Taxidermidades, de Salvador Pérez (https://www.taxidermidades.com/). Véase también Hochadel y Valls (2017).

21 Además, en 1882 se inaugura, en el antiguo Hospital de San Juan de Dios, el notable Museo Anatomo-Patológico de José Eugenio Olavide, conservado en su mayor parte hasta el día de hoy y que, pese a su denominación genérica original, estaba especializado en la presentación de enfermedades de la piel mediante impactantes ceroplastias (Conde-Salazar, 2006). Parece que no disponía de preparaciones (restos humanos) auténticas; en todo caso, hoy no existen.

22 La Soberanía Nacional, 15 de mayo de 1865 y El Anfiteatro Anatómico Español, 15 de julio de 1874.
23 Los términos entrecomillados se toman del inventario realizado en 1887 de forma previa a la adquisición del museo del doctor Velasco por el Estado. Se conserva en el archivo del actual Museo Nacional de Antropología (sign. $52 / 1887 / 5)$

24 Sobre el dramático caso de Luengo, enfermo de gigantismo y acromegalia que llegó a medir 2,30 m., puede consultarse Sánchez Gómez (2017a). Su piel disecada ya no se conserva, debió de ser destruida en la década de 1940. El actual Museo Nacional de Antropología sí exhibe el molde y el esqueleto.

25 Sobre las circunstancias que han limitado la taxidermia de humanos y para conocer algunos de los ejemplos más destacados, al margen de los que aquí se citan, véase Morris (2014).

26 Además del caso siguiente que refiero, debo anotar que en el propio domicilio de Velasco y su esposa, en el espacio que hoy ocupa la biblioteca del Museo Nacional de Antropología, el doctor guarda durante varios años el cuerpo momificado de su hija Conchita, fallecida en 1864. No obstante, nunca estuvo a la vista del público. Sobre la realidad y la leyenda de la hija del doctor Velasco, véase Sánchez Gómez (2017b).

27 Esta figura ya no se conserva; tampoco la del "negro" que se menciona a continuación. El museo guarda sendas figuras en yeso de una mujer y un varón khoikhois, y al menos una más de otro varón africano, pero fueron adquiridas mucho más tarde, durante la primera década del siglo $\mathrm{XX}$.

28 Museo Antropológico del Doctor Don Pedro González VeIasco. Inventario, folio 3 (manuscrito). Archivo del Museo Nacional de Antropología, sig. 52/1887/5.

29 Todas estas piezas se guardaban en el Museo de Ciencias Naturales. Sobre la enrevesada historia de las momias andinas, véase el artículo de Ortiz García en este mismo volumen. La momia guanche se traslada al Museo Arqueológico Nacional a finales de 2015.

30 Se ofrece un buen resumen sobre el "Negro de Banyoles" en la entrada correspondiente del citado blog de Salvador Pérez. Para un interesante estudio académico, véase Fock (2009).

31 Se conserva en el archivo del Museo Nacional de Antropología, con la signatura 57/1883/2

32 El precio triplica el de un elefante disecado que también tiene a la venta Darder (https://www.taxidermidades. com/2016/07/cronica-del-negro-de-banyoles.html).

\section{BIBLIOGRAFÍA}

Alberti, Samuel J. M. M.; Hallam, Elisabeth (eds.) (2013), Medical Museums. Past, Present, Future, Londres, The Royal College of Surgeons of England.

Azcárate Luxán, Isabel (2006), "Colecciones de Sanidad Militar", Revista de Museología, 37, pp. 201-208.
Bates, Alan W. (2008), “'Indecent and Demoralising Representations': Public Anatomy Museums in mid-Victorian England", Medical History, 52 (1), pp. 1-22.

Blanckaert Claude, (2013), La Vénus hottentote. Entre Barnum et Muséum, París, Muséum National d'Histoire Naturelle. 
Bolaños, María (comis.) (2018), La invención del cuerpo. Desnudos, anatomía, pasiones, Madrid, Ministerio de Cultura y Deporte, Secretaría General Técnica.

Castro, Francisco Javier de (1875), Catálogo de los museos y laboratorios de la Facultad de Medicina de Madrid, Madrid, Carlos Baylle Bailliere.

Conde-Salazar, Luis (ed.) (2006), Piel de cera. Olavide, San Juan de Dios y el Museo, Madrid, Luzán.

Delbourgo, James (2017), Collecting the World. The Life and Curiosity of Hans Sloane, Londres, Allen Lane.

Fock, Stefanie (2009), “'Un individu de raça negroide'. El Negro und die Wunderkammern des Rassismus". En: Hund, Wulf D. (ed.), Entfremdete Körper. Rassismus als Leichenschädung, Biellefeld, Transcript, pp. 165-204.

García Martín, Francisco (2012), El Gabinete de Historia Natural del Infante Don Luis Antonio en Boadilla del Monte, Toledo, Ledoria.

Guerrini, Anita (2016), “Inside the Charnel House: The Display of Skeletons in Europe, 1500-1800". En: Knoeff, R y Zwijnenberg, R. (eds.), The Fate of Anatomical Collections, Londres y Nueva York, Routledge, pp. 93-110.

Hallam, Elizabeth (2016), Anatomy Museum: Death and the Body Displayed, Londres, Reaktion Books.

Hochadel, Oliver; Valls, Laura (2017), “De Barcelona a Banyoles: Francesc Darder, la història natural aplicada i la Festa del Peix". En: Gómez, Crisanto; Massip, Josep M. y Figueras, Lluís (eds.), Dels museus de ciències del segle XIX al concepte museístic del segle XXI: Cent anys del Museu Darder de Banyoles, Banyoles, CECB, pp. 223-41.

Impey, Oliver; MacGregor, Arthur (eds.) (2017) [1985], The Origin of Museums. The Cabinet of Curiosities in Sixteenth - and Seventeenth-Century Europe, London, Ashmolean Museum.

López de la Vega, José (1871-72), “Museo Anatómico de la Facultad de Medicina de Madrid", El Genio Médico-Quirúrgico, 882 , pp. $605-607$; 886 , pp. $43-44$

MacGregor, Arthur (ed.) (1995), Sir Hans Sloane: Collector, Scientist, Antiquary, Founding Father of the British Museum, London, British Museum Press.

MacGregor, Arthur (2007), Curiosity and Enlightenment: Collectors and Collections from the Sixteenth to the Nineteenth Century, New Haven y London, Yale University Press.

Madoz, Pascual (1846), Diccionario geográfico-estadístico-histórico de España y sus posesiones de Ultramar. Tomo III, Madrid, Establecimiento literario-tipográfico de P. Madoz y L Sagasti.

Mariño, L.; Meseguer, M. A.; Baquero, M. (2018), “Papel de las colecciones de piezas anatómicas en la enseñanza de la anatomía patológica", Revista Española de Patología (en línea), disponible en: https://doi.org/10.1016/j.patol.2018.10.003, [consultado el 27/11/2018].

Morán Turina, J. M.; Checa Cremades, F. (1985), El coleccionismo en España. De la cámara de maravillas a la galería de pinturas, Madrid, Cátedra.
Morente Parra, Maribel (2016), "Modelando ciencia. La ceroplástica de Ignacio Lacaba en el Colegio de Cirugía de San Carlos de Madrid", Dynamis, 36 (1), pp. 27-45.

Morris, Pat (2014), "Stuffed Humans". En: Ebenstein, J. y Dickley, C. The Morbid Anatomy Anthology, Brooklyn, Nueva York, Morbid Anatomy Press, pp. 158-178.

Pardo Tomás, José (2010), “Escrito en la rebotica. Coleccionismo naturalista y prácticas de escritura en el gabinete de curiosidades de la familia Salvador. Barcelona, 1626-1857", Cultura Escrita \& Sociedad, 10, pp. 17-52.

Pardo Tomás, José y Zarzoso Orellana, Alfons (2017), “En la Facultad y en la Feria: hacia una geografía urbana de los museos anatómicos en Barcelona". En: Girón, A.; Hochadel, O. y Vallejo, G. (eds.), Saberes transatlánticos. Barcelona y Buenos Aires: conexiones, confluencias, comparaciones (1850-1940), Aranjuez, Doce Calles, pp. 189-214.

Pimentel, Juan (2010), El Rinoceronte y el Megaterio. Ensayo de morfología histórica, Madrid, Abada Editores.

Podgorny, Irina (2013), "Travelling Museums and Itinerant Collections in Nineteenth-Century Latin America", Museum History Journal, 6 (2), pp. 127-146.

Pulido Fernández, Ángel (1894), El Dr. Velasco, Madrid, Establecimiento tipográfico de E. Teodoro.

Revenga Domínguez, Paula (2014), "El coleccionismo ilustrado del cardenal Lorenzana. Entre España y México”. En: Flores, O. (coord.), El clasicismo en la época de Pedro José Márquez (1741-1820). Arqueología, filología, historia, música y teoría arquitectónica, México, UNAM, Instituto de Investigaciones Estéticas, Real Academia de Bellas Artes de San Fernando, pp. 205-221

Rey Bueno, M.; López Pérez, M. (eds.) (2008), The Gentleman, the Virtuoso, the Inquirer: Vincencio Juan de Lastanosa and the Art of Collecting in Early Modern Spain, Newcastle, Cambridge Scholars Publishing.

Ruud, Lise Camilla (2012), Doing Museum Objects in late Eighteenth-Century Madrid, Thesis submitted for the degree of Philosophiae Doctor, Faculty of Humanities, University of Oslo.

Ruud, Lise Camilla (2014), "'There is not one single thing that resembles this one'. Writing human monsters in late eighteenth-century Spain", Nordic Journal of Science and Technology Studies, 2 (1), pp. 62-69.

Sánchez Almazán, Javier (2013), “De las cámaras de maravillas a los gabinetes ilustrados". En Historias Naturales. Un proyecto de Miguel Ángel Blanco, Madrid, Museo del Prado, pp. 21-40.

Sánchez Almazán, Javier; Cánovas Fernández, Cristina (eds.) (2016), Una colección, un criollo erudito y un rey. Un gabinete para una monarquía ilustrada, Madrid, CSIC, Museo Nacional de Ciencias Naturales

Sánchez Gómez, Luis Ángel (2013), “¿Human Zoos or Ethnic Shows? Essence and contingency in Living Ethnological Exhibitions", Culture \& History Digital Journal, 2 (2) (en línea), disponible en: http://dx.doi.org/10.3989/chdj.2013.022, [consultado el 10/04/2018]. 
Sánchez Gómez, Luis Ángel (2014), “El Museo Antropológico del doctor Velasco (anatomía de una obsesión)", Anales del Museo Nacional de Antropología, XVI, pp. 265-297 (en línea), disponible en: https://sede.educacion.gob.es/publiventa/descarga.action?f_codigo_agc=14741C, [consultado el $22 / 02 / 2018$ ].

Sánchez Gómez, Luis Ángel (2015), “Una momia en el salón. Los museos anatómicos domésticos del doctor Velasco (1854-1874)", Asclepio, 67 (2) (en línea), disponible en: http://dx.doi.org/10.3989/asclepio.2015.29, [consultado el 10/04/2018]

Sánchez Gómez, Luis Ángel (2017a), “Anatomías míticas: el caso de Agustín Luengo Capilla, 'El Gigante Extremeño'”, Revista Historia Autónoma, 10, pp. 87-104 (en línea), disponible en: https://doi.org/10.15366/rha2017.10.005, [consultado el 18/05/2018]

Sánchez Gómez, Luis Ángel (2017b), La niña. Tragedia y leyenda de la hija del doctor Velasco, Sevilla, Renacimiento.

Sánchez Gómez, Luis Ángel 2018 “Un gigante americano en palacio (y su esqueleto en un museo)", Colonial Latin American Review, 26 (2), pp. 262-279.

Sánchez Hernández, María Leticia (ed.) (2015), El Relicario del Real Monasterio de la Encarnación de Madrid, Madrid, Patrimonio Nacional
Sappol, Michael (2004), “'Morbid curiosity': The Decline and Fall of the Popular Anatomical Museum", Common-Place, 4 (2) (en línea), disponible en http://common-place.org/ book/morbid-curiosity-the-decline-and-fall-of-the-popularanatomical-museum/, [consultado el 9/02/2018].

Schlosser, Julius von (1988) [1923], Las cámaras artísticas y maravillosas del Renacimiento tardío. Una contribución a la historia del coleccionismo, Madrid, Akal.

Sepibus, Georgius de Girgio de Sepi (1678), Romani Collegii Societatis Jesu Museum Celeberrimum [...], Ámsterdam, Janssonio Waesbergiana (en línea), disponible en https:// archive.org/details/gri 33125012933277/page/n6, [consultado el 9/02/2018].

Stephens, Elizabeth (2013) [2011], Anatomy as Spectacle. Public Exhibitions of the Body from 1700 to the Present, Liverpool, Liverpool University Press.

Zarzoso, Alfons; Pardo-Tomás, José (2016), "Fall and Rise of the Roca Museum: Owners, Meanings and Audiences of an Anatomical Collection from Barcelona to Antwerp, 19222012". En: Knoeff, R. y Zwijnenberg, R. (eds.), The Fate of Anatomical Collections, London and New York, Routledge, pp. 161-176. 